\title{
Measurement of gas-phase ammonia and amines in air by collection onto an ion exchange resin and analysis by ion chromatography
}

\author{
M. L. Dawson, V. Perraud, A. Gomez, K. D. Arquero, M. J. Ezell, and B. J. Finlayson-Pitts \\ Department of Chemistry, University of California, Irvine, California, USA \\ Correspondence to: B. J. Finlayson-Pitts (bjfinlay@uci.edu)
}

Received: 29 January 2014 - Published in Atmos. Meas. Tech. Discuss.: 14 February 2014

Revised: 30 June 2014 - Accepted: 15 July 2014 - Published: 26 August 2014

\begin{abstract}
Ammonia and amines are common trace gases in the atmosphere and have a variety of both biogenic and anthropogenic sources, with a major contribution coming from agricultural sites. In addition to their malodorous nature, both ammonia and amines have been shown to enhance particle formation from acids such as nitric, sulfuric and methanesulfonic acids, which has implications for visibility, human health and climate. A key component of quantifying the effects of these species on particle formation is accurate gasphase measurements in both laboratory and field studies. However, these species are notoriously difficult to measure as they are readily taken up on surfaces, including onto glass surfaces from aqueous solution as established in the present studies. We describe here a novel technique for measuring gas-phase ammonia and amines that involves uptake onto a weak cation exchange resin followed by extraction and analysis using ion chromatography. Two variants - one for parts per billion concentrations in air and the second with lower (parts per trillion) detection limits - are described. The latter involves the use of a custom-designed high-pressure cartridge to hold the resin for in-line extraction. These methods avoid the use of sampling lines, which can lead to significant inlet losses of these compounds. They also have the advantages of being relatively simple and inexpensive. The applicability of this technique to ambient air is demonstrated in measurements made near a cattle farm in Chino, CA.
\end{abstract}

\section{Introduction}

Atmospheric aerosol particles are known to reduce visibility and adversely affect human health. They also impact the climate as they are able to scatter and absorb solar radiation and serve as cloud and ice condensation nuclei (Finlayson-Pitts and Pitts, 2000; Seinfeld and Pandis, 2006). Ammonia and amines are routinely detected in the particle phase and have been identified as important contributors to new particle formation and growth (Angelino et al., 2001; Berndt et al., 2010; Bzdek and Johnston, 2010; Bzdek et al., 2011; Chen et al., 2012; Creamean et al., 2011; Dawson et al., 2012; Loukonen et al., 2010; Müller et al., 2009; Ruiz-Jiménez et al., 2012; Smith et al., 2010; VandenBoer et al., 2011). Accurate measurement of gas-phase ammonia and amines both in the atmosphere and in laboratory experiments is a key component of understanding and quantifying their role in particle chemistry and physics.

Atmospheric ammonia and amines have a wide variety of sources, both biogenic and anthropogenic (Ge et al., 2011a, b). Industrial and agricultural practices involving animals, e.g., cattle feed lots or swine facilities (Anderson et al., 2003; Hiranuma et al., 2010; Kuhn et al., 2011; Mosier et al., 1973; Ni et al., 2012; Schade and Crutzen, 1995), are significant sources of these species in the atmosphere. Agricultural emissions of ammonia and short-chain aliphatic amines, in particular, account for a large fraction of the global flux of these species into the atmosphere (Ge et al., 2011a, b; Schade and Crutzen, 1995). In addition to agricultural sources, humans, animals (both wild and domestic), sewage, industry and transportation are important sources of ammonia in urban areas (Li et al., 2006; Perrino et al., 2002; Sutton et al., 2000; Whitehead et al., 2007). Other sources of amines and ammonia include ocean biota (Ge et al., 2011a; Gibb et al., 1999), biomass burning (Ge et al., 2011a; Lobert et al., 1990), and release from carbon capture and storage devices that use amines to trap $\mathrm{CO}_{2}$, which could be a more important source of atmospheric amines and ammonia as the technol- 
ogy becomes more widely adopted (Borduas et al., 2013; Ge et al., 2011a; Nielsen et al., 2012; Rochelle, 2009; Schreiber et al., 2009).

Importantly, it has been shown that gas-phase ammonia and amines significantly enhance particle formation from common atmospheric acids, such as sulfuric, nitric and methanesulfonic acids (Almeida et al., 2013; Angelino et al., 2001; Berndt et al., 2010; Chen et al., 2012; Dawson et al., 2012; Loukonen et al., 2010; Smith et al., 2010; Yu et al., 2012), and contribute to growth of atmospheric nanoparticles (Barsanti et al., 2009; Bzdek et al., 2011; Smith et al., 2010; Wang et al., 2010). Short-chain alkyl amines have been shown to displace ammonia in particles (Bzdek et al., 2010, 2011; Chan and Chan, 2012; Liu et al., 2012; Lloyd et al., 2009), which enhances their importance in particle formation and growth. Although amines are short-lived in the atmosphere due to oxidation by common atmospheric oxidants such as $\mathrm{OH}$ and $\mathrm{O}_{3}$ (Nielsen et al., 2012; Tang et al., 2013), amines and the precursors to sulfuric and methanesulfonic acids (Bates et al., 1992; Ge et al., 2011a; Ni et al., 2012) are in sufficiently close temporal proximity in the atmosphere that they are important contributors to particle formation.

Reliable data on the sources, sinks, and ambient concentrations of gas-phase amines, therefore, are crucial to predicting new particle formation in the atmosphere. However, gasphase amines are notoriously difficult to measure and typical concentrations in the atmosphere are of the order of a few parts per billion or less (Ge et al., 2011a). Several techniques for measuring gas-phase ammonia and amines have been reported in the literature. On-line mass spectrometric (MS) techniques include ambient pressure proton transfer MS (Hanson et al., 2011), chemical ionization MS (Yu and Lee, 2012), and proton transfer reaction MS (PTR-MS) (Borduas et al., 2013; Feilberg et al., 2010; Kuhn et al., 2011; Liu et al., 2011; Tanimoto et al., 2007). Off-line techniques typically involve collection of a gas-phase sample onto a substrate (e.g., activated charcoal or an acid-impregnated glass fiber filter) (Fournier et al., 2008; Fuselli et al., 1982), into an acidic solution (Akyüz, 2008; Gronberg et al., 1992; Schade and Crutzen, 1995), or onto a whetted glass frit (Huang et al., 2009). Samples are then extracted and analyzed using gas or liquid chromatography, sometimes with a derivatization step included (Akyüz, 2008; Fuselli et al., 1982; Gronberg et al., 1992; Hiranuma et al., 2010; Huang et al., 2009; Nishikawa and Kuwata, 1984; Santagati et al., 2002; Schade and Crutzen, 1995). Ion chromatography (IC) has also proven to be useful for both gas- and particle-phase ammonia and amines (Gibb et al., 1999; Hiranuma et al., 2010; Orsini et al., 2003; Praplan et al., 2012; VandenBoer et al., 2011). Formation of an indophenol complex which is measured spectrometrically has been developed for ammonia (Scheiner, 1976; Solórzano, 1969), as have various techniques involving the formation of 1-sulfonatoisoindole followed by fluorescence measurement (Toda et al., 2010; Zhang et al., 1989). For atmospheric ammonia measurement techniques, several intercomparison studies, in both field and laboratory settings, have been reported in the literature (von Bobrutzki et al., 2010; Fehsenfeld et al., 2002; Kirchner et al., 1999; Norman et al., 2009; Schwab et al., 2007; Wiebe et al., 1990; Williams et al., 1992).

An important limitation to many existing techniques for measuring ammonia and amines is deposition of the gasphase analyte onto instrument surfaces prior to measurement, which varies with the compound (Hansen et al., 2013). Also, it has recently been shown that amines are irreversibly taken up onto surfaces that have been exposed to a gas-phase acid, forming a non-volatile salt (Nishino et al., 2013). As a variety of acids and acid precursors are present in the atmosphere, this loss may have a significant effect on measurement efficiency for instrumentation where the gas-phase sample is in contact with surfaces such as tubing prior to measurement, even when these surfaces are heated. In addition, amines in aqueous solution are shown here to be subject to uptake on glass, with implications for measurement techniques.

This work demonstrates the use of a weak cation exchange (WCE) resin as a substrate for efficient collection of gasphase ammonia and amines at atmospherically relevant concentrations, followed by analysis by IC. While ion exchange resins have been used in a variety of environmental sampling techniques involving liquid-phase samples (Fenn et al., 2002; Simkin et al., 2004; Skogley and Dobermann, 1996; Templer and Weathers, 2011), to the authors' knowledge this is the first demonstration of its ability to efficiently collect molecular species from a gas-phase sample. In this work, two approaches were developed. The first is applicable to higher (parts per billion) concentrations while the second, for which a custom high-pressure resin holder cartridge was designed for in-line extraction on an IC system, has detection limits in the tens of parts per trillion range. These methods were developed to minimize the sampling losses reported previously whilst also being capable of measuring ammonia and amines at the parts per trillion level in air.

The method we present here is well suited to laboratory studies where gas-phase ammonia and amine measurements are often required in the absence of particles. In the atmosphere, ammonia and amines are typically present in both the gas and particle phase, and several techniques have been developed to measure species in the two phases separately (ten Brink et al., 2007; Gibb et al., 1999; Markovic et al., 2012; Orsini et al., 2003; Trebs et al., 2004; VandenBoer et al., 2011). While differentiation of ammonia and amines in the gas phase vs. particle phase is beyond the scope of this work, we also demonstrate the efficiency of this technique for measuring total gas- and particle-phase ammonia and amines. If differentiating gas- and particle-phase species is desired, this technique could be used in combination with a denuder, which removes the gas phase prior to measurement. 


\section{Experimental}

\subsection{Liquid-phase standards}

Standard solutions for ammonia, methylamine (MA), dimethylamine (DMA), and trimethylamine (TMA) were prepared from their chloride salts in $0.1 \mathrm{M}$ oxalic acid (Fluka). These include $\mathrm{NH}_{4} \mathrm{Cl}$ (Sigma, $99.5 \%$ ), $\mathrm{CH}_{3} \mathrm{NH}_{3} \mathrm{Cl}$ (Aldrich, 98.0\%), $\left(\mathrm{CH}_{3}\right)_{2} \mathrm{NH}_{2} \mathrm{Cl}$ (Aldrich, $99.0 \%$ ), and $\left(\mathrm{CH}_{3}\right)_{3} \mathrm{NHCl}$ (Aldrich, $98.0 \%$ ).

In the course of developing this method, there was some indication that amines and/or aminium ions in aqueous solution were being taken up onto the walls of glass containers. To test whether, and to what extent, this was occurring, a standard solution containing between 10 and $30 \mathrm{ng} \mathrm{mL}^{-1}$ of the ammonium and aminium species in nanopure water was prepared and stored in plastic (polypropylene or Nalgene) containers. A portion of this solution was placed in three $20 \mathrm{~mL}$ glass scintillation vials half filled with clean, dry borosilicate glass beads (Chemglass; P/N CG-1101-02) and allowed to sit for $60 \mathrm{~min}$. The original standard solution (stored only in plastic) and those from the glass vials were then analyzed by IC. The peaks in the samples from the glass vials corresponding to ammonia and the amines were reduced, on average, by $13-23 \%$ compared to the original standard solution, indicating that amines are taken up by glass surfaces under neutral conditions. However, it should be noted that when the standard solution was acidic, no uptake on glass was observed. The stability of the IC signal response to standards kept in plastic over several weeks, as well as the linearity of the calibration curves, suggests that no significant uptake on plastic occurs. The relative standard deviation of the peak area for ammonia and the three amines from measurements of the same standard solution over the course of 27 days was $<2 \%$ for each species. To avoid any potential wall loss, no glass was used in the preparation or storage of standards and samples used in this study.

\subsection{Gas-phase standards}

Mixtures of ammonia (Airgas; $0.812 \mathrm{ppm}$ in $\mathrm{N}_{2}$ ), MA (Airgas; $10 \mathrm{ppm}$ in $\mathrm{N}_{2}$ ), DMA (Airgas; $1.0 \mathrm{ppm}$ in $\mathrm{N}_{2}$ ), and TMA (Airgas; $1.0 \mathrm{ppm}$ in $\mathrm{N}_{2}$ ) in nitrogen were used to test the collection efficiency of the cation exchange resin (stated concentrations were those provided by the manufacturer but, as discussed below, have considerable uncertainties associated with them). Gas-phase ammonia and amines from the gas cylinders were diluted with clean, dry air from a Fourier transform infrared spectroscopy purge air generator (ParkerBalston; Model 75-62) for a total flow of 4.0 $\mathrm{L} \mathrm{min}^{-1}$ and analyte concentrations of approximately $2-1000 \mathrm{ppb}$ as shown in Fig. 1. Gas cylinder and purge-air flows were maintained using mass flow controllers (Alicat).

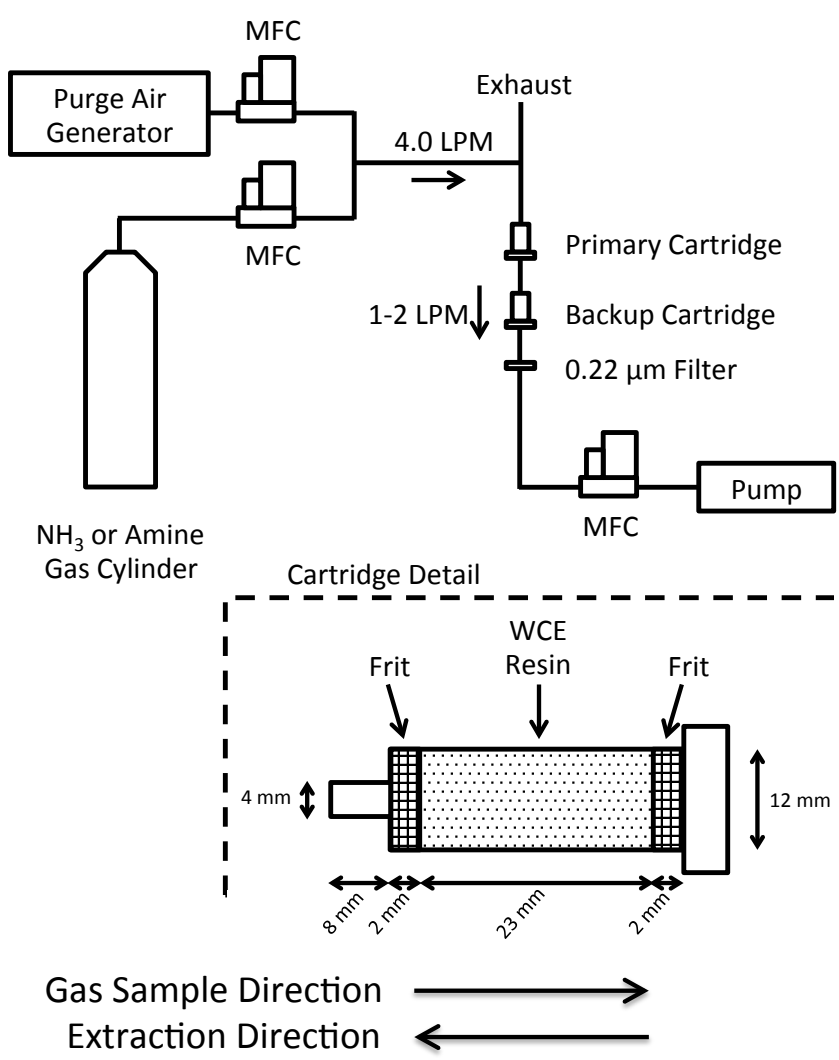

Figure 1. Schematic of experimental system used to determine cartridge measurement efficiency. MFC: mass flow controller. Inset shows a detailed view of the "high-concentration" cartridge.

\subsection{Cartridge preparation and analysis for higher (ppb) concentrations}

Sampling cartridges were prepared by filling $2.5 \mathrm{~mL}$ nonfluorous polypropylene cartridges (Supelco; model 57602U) with WCE resin (Resintech, model WACG) between two polyethylene frits (Supelco) as shown in Fig. 1 (inset). WCE resin consists of acrylic/divinylbenzene beads terminated with carboxylic acid groups. The design of the cartridges minimizes the surfaces in contact with the sample prior to adsorption on the WCE resin, and those that are exposed are subsequently extracted with the resin. These cartridges were used to sample gas-phase standards in the ppbppm range in air to characterize the collection and extraction efficiency of WCE resin, and will be referred to as "highconcentration cartridges".

Samples were collected for $20 \mathrm{~min}$ at $1-2 \mathrm{~L} \mathrm{~min}^{-1}$ maintained using a mass flow controller (Alicat). Two cartridges in series (Fig. 1, hereafter referred as "primary" and "backup" cartridges) were used in all experiments to determine collection efficiency. Cartridges were extracted and regenerated by flushing five times with $10.0 \mathrm{~mL} 0.1 \mathrm{M}$ oxalic acid (Fluka) to remove the collected ammonia and amines and return the resin to its protonated (-R-COOH) form. The 
a)

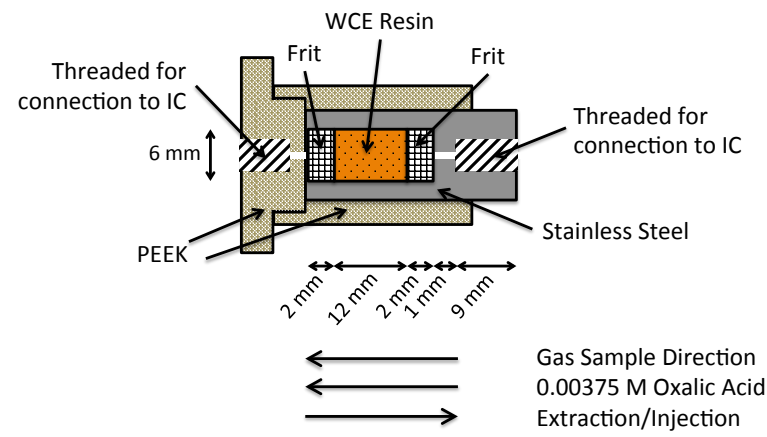

b)

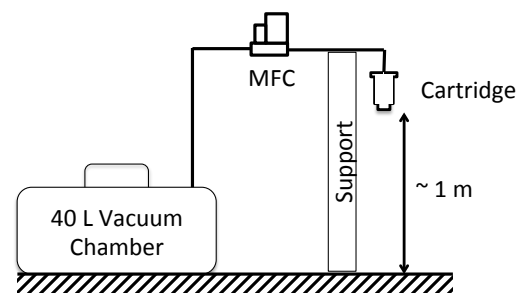

Figure 2. Schematics of (a) "low-concentration" cartridge and (b) configuration for field sampling using "low-concentration" cartridges. MFC: battery-operated mass flow controller.

first $10.0 \mathrm{~mL}$ extract was used as the sample. For the primary cartridge, the first two $10.0 \mathrm{~mL}$ extractions were analyzed to determine extraction efficiency. The cartridge was flushed another three times with $10.0 \mathrm{~mL} 0.1 \mathrm{M}$ oxalic acid, and the final rinse was used as a blank for the subsequent sample. Samples were stored in $11 \mathrm{~mL}$ polypropylene vials (Metrohm, KITIC0008) prior to measurement.

Samples were analyzed by IC (Metrohm, model 850) with a Metrosep C4-250/4.0 cation column and equipped with a conductivity detector. The IC eluent was $0.00375 \mathrm{M}$ oxalic acid, and the flow rate was $0.9 \mathrm{~mL} \mathrm{~min}^{-1}$. The IC column temperature was maintained at $30^{\circ} \mathrm{C}$. The sample loop was $20 \mu \mathrm{L}$, and the total elution time was $24 \mathrm{~min}$.

\subsection{Cartridge preparation and analysis for lower (ppt) concentrations by in-line extraction and analysis}

For ambient sampling, modified cartridges (Fig. 2) that could be used under the high-pressure conditions of the IC were designed for gas-phase collection and in-line extraction (see below). It should be noted that "in-line" here refers to the method of extraction on the IC column and does not indicate that this is an on-line measurement technique. These cartridges were prepared using a PEEK analytical guard cartridge holder (Hamilton; model 79477) designed for use on high-pressure liquid chromatography systems and a custombuilt stainless-steel insert containing WCE resin (Resintech, model WACG) between two polyethylene frits (Supelco). These are referred to as "low-concentration cartridges" in the subsequent discussion. As for the "high-concentration" cartridge, this design minimizes the amount of surface area that

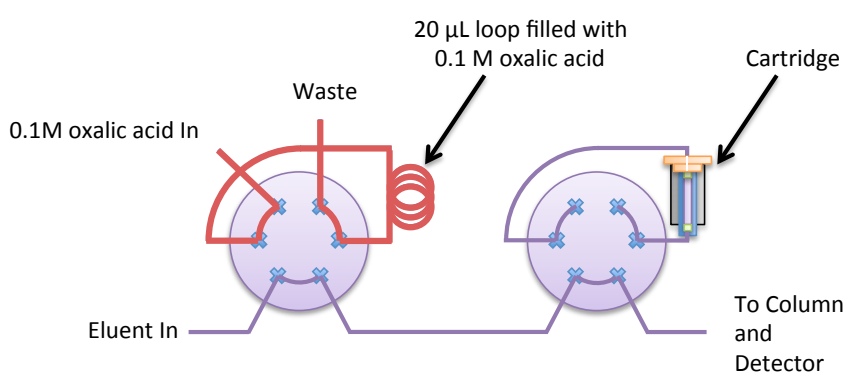

Figure 3. Schematic of the in-line system for simultaneous extraction and analysis of ammonia and amine samples by IC (shown immediately prior to injection). At the beginning of the IC run, both injectors are actuated, allowing the $0.1 \mathrm{M}$ oxalic acid plug to extract the cartridge and push the amine/ammonia onto the IC column.

gas-phase samples are in contact with prior to adsorption on the WCE resin to $\sim 1 \mathrm{~cm}^{2}$ of stainless steel and one of the polyethylene frits; however, adsorbates on both the frit and stainless steel are extracted along with those on the resin.

Prior to sampling, the low-concentration cartridges were flushed three times with $10.0 \mathrm{~mL} 0.1 \mathrm{M}$ oxalic acid followed by clean, dry air for $20 \mathrm{~min}$ at $150 \mathrm{~cm}^{3} \mathrm{~min}^{-1}$ to remove residual water from the last rinse. Gas-phase samples were pumped through the cartridge at $150 \mathrm{~cm}^{3} \mathrm{~min}^{-1}$ for $45-$ $50 \mathrm{~min}$ in the direction indicated in Fig. 2. After sampling, the cartridge was filled with $60-80 \mu \mathrm{L} 0.00375 \mathrm{M}$ oxalic acid (IC eluent) using a syringe pump (New Era Pump Systems; Mod \#NE-1000) in the same direction as the gas-phase sample (Fig. 2), to avoid injecting air into the IC system. The volume of eluent used to fill the cartridges was $\sim 5-10 \mu \mathrm{L}$ lower than their predetermined capacity to prevent overfilling and loss of analyte. Any residual air left in the cartridges was not sufficient to cause problems during the IC runs.

Extraction and analysis were performed in-line on the IC by using two injectors in series, as shown in Fig. 3. This procedure eliminates the separate extraction step and allows the entire collected sample to be injected onto the IC column, as opposed to extracting the cartridge with $10 \mathrm{~mL}$ of $0.1 \mathrm{M}$ oxalic acid and then analyzing a $20 \mu \mathrm{L}$ portion of the extract on the IC. Having the entire collected sample injected onto the IC column lowers the detection limit to a range suitable for atmospheric concentrations (Table 1). The first injector sample loop was loaded with $20 \mu \mathrm{L} 0.1 \mathrm{M}$ oxalic acid, and the second injector was fitted with the low-concentration cartridge in place of a sample loop, oriented so the IC eluent flow will be in the direction indicated in Fig. 2. All other IC conditions were as described in Sect. 2.3.

At the beginning of the run, the sample loop containing the acid and the low-concentration cartridge were simultaneously injected. This allows the concentrated oxalic acid plug to extract the cartridge and push the analyte onto the column. After $0.25 \mathrm{~min}$, the cartridge injector was returned to fill mode. Three to five sequential extractions of the cartridge 
were performed for each sample, depending on the measured ammonia and/or amine concentrations.

A series of experiments was performed to determine if breakthrough occurs in the low-concentration cartridges under conditions of high ammonia concentration as is often seen in the field samples (Ge et al., 2011a, b). Three lowconcentration cartridges were prepared as described above, and one was kept as a blank. Gas-phase ammonia in $\mathrm{N}_{2}$ from a gas cylinder (Airgas; $0.812 \mathrm{ppm}$ in $\mathrm{N}_{2}$ ) was then flowed through the remaining two cartridges in series for $50 \mathrm{~min}$ at $150 \mathrm{~cm}^{3} \mathrm{~min}^{-1}$. Three sets of samples were taken. After background subtraction, the measured $\mathrm{NH}_{3}$ concentration on the backup cartridge was less than $7 \%$ of the total measured $\mathrm{NH}_{3}$ (primary + backup) in all three cases, and was $4 \%$ of the total measured $\mathrm{NH}_{3}$ on average. These results suggest minimal breakthrough occurs, even with high ammonia concentrations.

\subsection{Field measurements in an agricultural area}

Several field measurements using the low-concentration cartridges were performed in Chino, CA, USA. Sampling conditions including sample time and flow rate were as described in Sect. 2.4. A $40 \mathrm{~L}$ steel chamber under vacuum was used as the pump. It was evacuated, fitted with a batterypowered mass flow controller (Alicat) and used to maintain sample flow through the cartridges (Fig. 2b). This allowed sampling to be performed away from a power source without the need for a generator, which could have introduced exhaust-related artifacts. Samples were taken approximately $50 \mathrm{~m}$ away from cattle pens and $\sim 1 \mathrm{~m}$ above the ground between 4 a.m. and 6 a.m. LT (before sunrise) between $28 \mathrm{Au}$ gust and 12 September 2013. On each day, one cartridge was prepared as described in Sect. 2.4 and kept as a blank. These blanks were used for background subtraction of the sample chromatograms.

\section{Results and discussion}

A typical chromatogram for the liquid standards is shown in Fig. 4. Peaks corresponding to $\mathrm{NH}_{4}^{+}$, MA- $\mathrm{H}^{+}$, DMA-H ${ }^{+}$, TMA- $\mathrm{H}^{+}$and a small amount of $\mathrm{Na}^{+}$are present. Table 1 summarizes retention times and liquid-phase detection limits for ammonia, MA, DMA and TMA. These were calculated as the average concentration whose signal corresponds to $3 / 5$ of the peak-to-peak noise from 10 typical cartridge measurements (Skoog et al., 1998). The standard deviation of this value is a measure of reproducibility. Errors in the estimated detection limits shown in Table 1 are \pm two sample standard deviations. For the high-concentration cartridges, gasphase detection limits were calculated for $20 \mathrm{~min}$ samples at $1.0 \mathrm{~L} \mathrm{~min}^{-1}$ sample flow followed by extraction in $10 \mathrm{~mL}$ $0.1 \mathrm{M}$ oxalic acid. For the low-concentration cartridges, gasphase detection limits were calculated for 60 min samples at

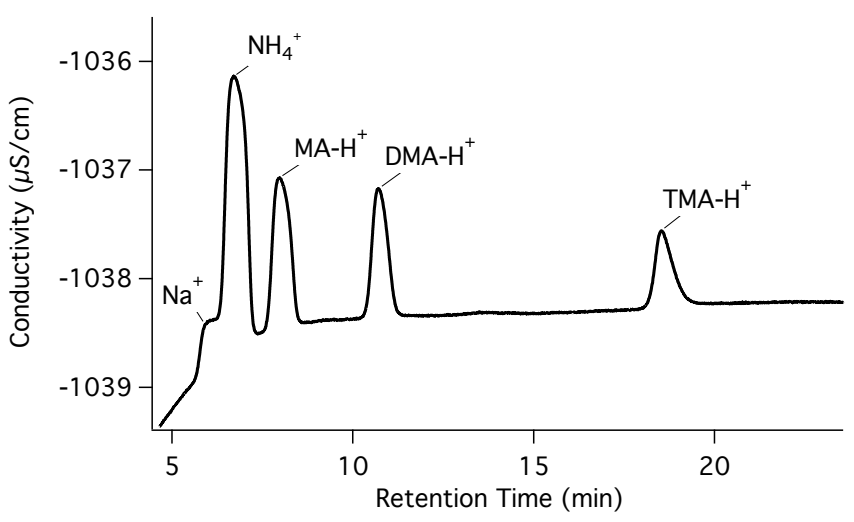

Figure 4. A typical ion chromatogram for the amine/ammonia standards in $0.1 \mathrm{M}$ oxalic acid. Standards also included sodium methanesulfonate $\left(\mathrm{NaCH}_{3} \mathrm{SO}_{3}\right.$; Aldrich; $\left.98 \%\right)$ because of the nature of ongoing laboratory experiments at the time so that $\mathrm{Na}^{+}$was also present.

$150 \mathrm{~cm}^{3} \mathrm{~min}^{-1}$ sample flow followed by in-line extraction on the IC. Detection limits for the high- and low-pressure cartridges were in the low parts per billion and parts per trillion range, respectively (see Table 1). It should be noted that, with the current design of the low-concentration cartridges, $150 \mathrm{~cm}^{3} \mathrm{~min}^{-1}$ is the maximum sample flow possible. However, redesigning the cartridge to allow higher sampling flow would further lower the detection limits for this method.

\subsection{Gas-phase standards using the high-concentration cartridges with off-line extraction}

Oxalic acid is not retained by the cation column used in the IC and elutes at $\sim 2.5 \mathrm{~min}$. The high concentration $(0.1 \mathrm{M})$ of oxalic acid in the cartridge extracts compared to that of the IC eluent $(0.00375 \mathrm{M})$ results in a characteristic negative broad signal initially as can be seen in a typical cartridge blank (Fig. 5a). For this reason, blanks are subtracted from cartridge samples before the peaks are integrated. A typical background-subtracted chromatogram for a DMA sample is shown in Fig. 5b. Results from the gas-phase standard measurements are presented in Fig. 6 and show measured ammonia and amine concentrations for the first and second extract of the primary cartridge, the first extract of the backup cartridge, as well as the total measured concentration (first and second extract of the primary cartridge plus the first extract of the backup cartridge).

WCE resin was originally designed to remove alkaline components from liquid solutions by reaction with the surface carboxylic acid groups (Kunin and Barry, 1949). To the best of our knowledge, its ability to take up gas-phase species has not been reported. For the three amines, the measured concentration from the backup cartridge was less than $5 \%$ of that of the primary cartridge (Fig. 6). This small amount of breakthrough indicates that WCE resin efficiently takes 
Table 1. Retention times and calculated detection limits for ammonia and amines. Errors shown are $\pm 2 \mathrm{~s}$.

\begin{tabular}{|c|c|c|c|c|}
\hline \multirow{2}{*}{ Species } & \multirow{2}{*}{$\begin{array}{l}\text { Retention } \\
\text { time (min) }\end{array}$} & \multirow{2}{*}{$\begin{array}{l}\text { Liquid-phase detection } \\
\text { limit }^{\mathrm{a}}\left(M \times 10^{-7}\right)\end{array}$} & \multicolumn{2}{|c|}{ Gas-phase detection limit ${ }^{\mathrm{a}, \mathrm{b}}$} \\
\hline & & & $\begin{array}{l}\text { High-concentration } \\
\text { cartridge (ppb in air) }\end{array}$ & $\begin{array}{l}\text { Low-concentration } \\
\text { Cartridge (ppt in air) }\end{array}$ \\
\hline Ammonia & 7.5 & $2.3 \pm 1.6$ & $2.8 \pm 1.9$ & $12 \pm 8$ \\
\hline Methylamine & 8.8 & $2.6 \pm 1.7$ & $3.1 \pm 2.1$ & $14 \pm 9$ \\
\hline Dimethylamine & 11.8 & $3.5 \pm 2.4$ & $4.3 \pm 3.0$ & $19 \pm 13$ \\
\hline Trimethylamine & 20.7 & $8.2 \pm 5.6$ & $10 \pm 7$ & $45 \pm 31$ \\
\hline
\end{tabular}

${ }^{a}$ Detection limits are calculated from the average of the signal corresponding to $3 / 5$ peak-to-peak noise from 10 cartridge samples.

${ }^{\mathrm{b}}$ Gas-phase detection limits for the high-concentration cartridge samples are based on 1 LPM sampling for 20 min, extraction in $10 \mathrm{~mL}$ oxalic acid, and injection of $20 \mu \mathrm{L}$ of the solution. For the low-concentration cartridge, detection limits are based on $150 \mathrm{~cm}^{3} \mathrm{~min}^{-1}$ sampling for $60 \mathrm{~min}$ and in-line extraction on the IC.
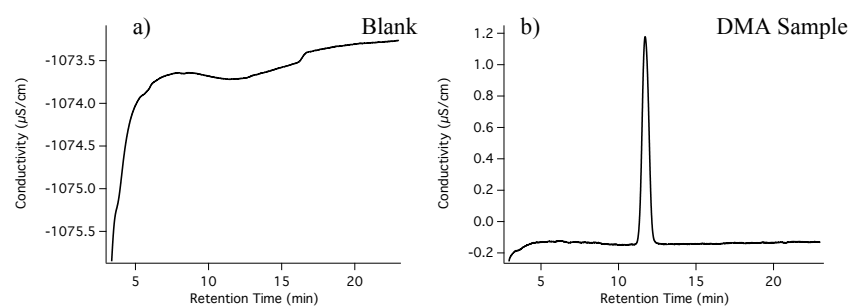

Figure 5. (a) Chromatogram for a typical blank using highconcentration cartridges showing the characteristic baseline due to the high oxalic acid concentration in the cartridge extracts and (b) a background subtracted ion chromatogram for a DMA sample (nominally $1.0 \mathrm{ppm}$ in $\mathrm{N}_{2}$; see Sect. 3.1).

up gas-phase amines even at the relatively high flow rate of $1.0 \mathrm{~L} \mathrm{~min}^{-1}$. For ammonia, this value is slightly higher ( $<10 \%$ of the primary cartridge), suggesting that the lessbasic, more-volatile ammonia is trapped less efficiently than the amine species.

For cartridge extraction, an appropriate solvent must be able to efficiently extract the ammonia and amines, and be low enough in concentration to minimize effects on the baseline in the ion chromatogram (Fig. 5a). For regeneration of the WCE resin, the manufacturer recommends dilute hydrochloric or sulfuric acids. In our experiments, we chose oxalic acid as the extraction solvent due to its weak acidity $\left[p K_{\mathrm{a} 1}=1.25 ; p K_{\mathrm{a} 2}=3.81\right]$ (Haynes, 2013) and its use as the IC eluent. As seen in Fig. 6, the second extract of the primary cartridge using $10.0 \mathrm{~mL}$ of $0.1 \mathrm{M}$ oxalic acid contains less than $15 \%$ of the analyte compared to that of the first extraction, indicating this method efficiently extracts the collected species. However, oxalic acid concentrations lower than $0.1 \mathrm{M}$ were shown not to be sufficient. For DMA and TMA, a slight trend of increasing concentration of amine measured from the second extraction of the primary cartridge is evident, suggesting that, at higher gasphase concentrations, a shorter sample time, lower flow rate or multiple extractions may be required. However, such high concentrations of the amines ( $>0.5 \mathrm{ppm}$ ) have not been reported in air and hence are unlikely to present an analytical limitation for this technique as an ambient sampling method.

Figure 6 shows weighted least-squares fits (green lines) forced through $[0,0]$ of the total measured concentrations of ammonia and the amines. These data indicate a linear trend of measured concentration with dilution and suggest good measurement efficiency for each of the gas-phase amines and ammonia. Error bars shown for individual data points are \pm two sample standard deviations, and are based on at least three individual measurements. These values are used to calculate the errors in the weighted least-squares slopes shown in Fig. 6, which are a measure of the precision of this technique and are $2-15 \%$ for ammonia, MA, DMA and TMA. These values are similar to those obtained for other techniques that have used gas-phase amine standards for characterization (Fournier et al., 2008). In addition, they likely represent an upper limit to the error associated with this technique as the system used to generate the gas-phase standards (Fig. 1) involves carefully regulated flow rates and many hours of conditioning. Some of the variability in the measurements, no doubt, reflects variability in the actual gas-phase concentrations and therefore is not intrinsic to the measurement technique.

As can be seen in Fig. 6, the measured concentrations without dilution are lower than the manufacturer-provided concentrations of the gas cylinders (see Sect. 2.2). While this could potentially be due to uptake of the amines on tubing walls prior to measurement, this seems unlikely as the system was conditioned for several hours at each concentration prior to sampling and no trend of increasing concentration was observed after conditioning. It is possible that the labeled concentrations of the cylinders are artificially high, as the manufacturer has expressed difficulty in preparing such low concentrations of these sticky compounds. The linear trend with dilution along with the negligible amounts measured in the backup cartridge and second extract of the primary cartridge indicate efficient measurement for this technique. To explore this further, two of the gas cylinders $\left(\mathrm{NH}_{3}\right.$ 

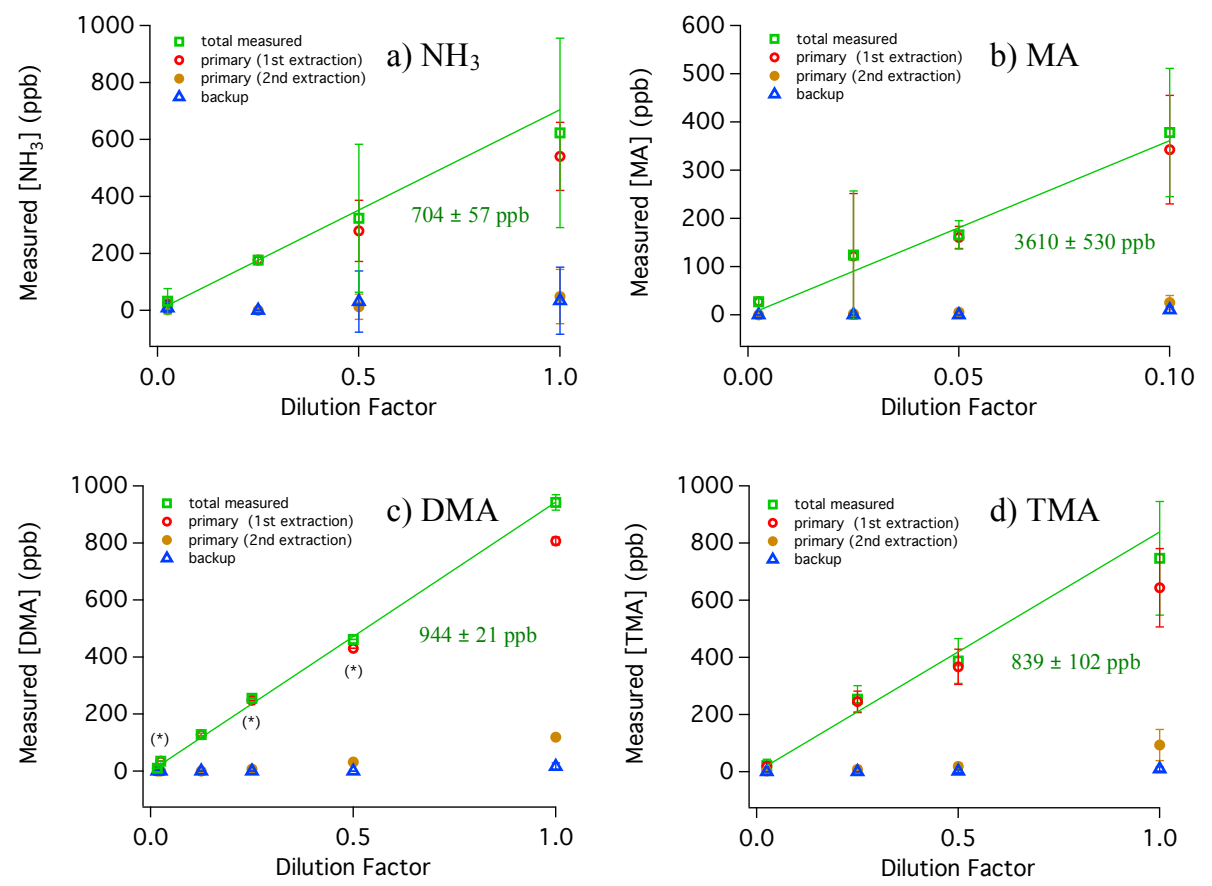

Figure 6. Results for measurements of gas-phase standards of (a) ammonia, (b) MA, (c) DMA, and (d) TMA using high-concentration cartridges, including the first and second extract of the primary cartridge and the first extract of the backup cartridge, as well as the total measured concentrations. The dilution factor for ammonia or amine from the gas cylinders diluted in air is shown on the $x$ axis, where 1.0 is the undiluted standard and 0.1 is a $10 \%$ mixture. Data points marked with an asterisk $(*)$ do not have sufficient replicates to include error bars. The green lines are weighted least-squares fits, where the weights for each point are given by $w=\left(1 \mathrm{~s}^{-2}\right)$ and s is the sample standard deviation of the measurements at each dilution. Slopes of fitted lines are shown in green $( \pm 2 \mathrm{~s})$. Labeled concentrations for the undiluted standards were $0.812 \mathrm{ppm} \mathrm{NH}_{3}, 10 \mathrm{ppm} \mathrm{MA,} 1.0 \mathrm{ppm}$ DMA, and $1.0 \mathrm{ppm}$ TMA.

and MA) were analyzed by a different technique. Samples from the cylinders were bubbled through a $0.1 \mathrm{M}$ oxalic acid solution at $30 \mathrm{~cm}^{3} \mathrm{~min}^{-1}$ for $60 \mathrm{~min}$, which was then analyzed by IC. These measured concentrations agreed with those measured by cartridge collection within experimental error $\left(\left[\mathrm{NH}_{3}\right]=575 \pm 128 \mathrm{ppb} ;[\mathrm{MA}]=4.40 \pm 0.58 \mathrm{ppm}\right)$. This comparison of measured to nominal concentrations also provides a cautionary note in terms of using commercially supplied amine or ammonia gas mixtures as calibration standards.

All the samples for the gas-phase standard measurements (both primary and backup) were collected on four highconcentration cartridges. These cartridges showed no noticeable degradation in collection or extraction efficiency, even after hundreds of extractions without replacing the WCE resin.

As a further test of the reproducibility of this technique, two low-concentration cartridges were used to simultaneously sample air above solutions of $40 \%$ MA and TMA in $\mathrm{H}_{2} \mathrm{O}$. Samples were taken at $100 \mathrm{~cm}^{3} \mathrm{~min}^{-1}$ for $60 \mathrm{~min}$ and analyzed as described in Sect. 2.4. The total concentrations of amine measured by each cartridge after five extractions were compared and found to be within $9 \%$ (MA) and $15 \%$ (TMA) of each other.
To test the efficiency of this method for collection of particle-phase species, experiments were performed using high-concentration cartridges to sample $\left(\mathrm{NH}_{4}\right)_{2} \mathrm{SO}_{4}$ particles under dry conditions and at $\sim 30 \% \mathrm{RH}$. Particles of $\left(\mathrm{NH}_{4}\right)_{2} \mathrm{SO}_{4}$ were generated by atomizing a dilute solution of $\left(\mathrm{NH}_{4}\right)_{2} \mathrm{SO}_{4}$. A flow of 2.4 LPM from the atomizer was dried using a Nafion dryer (PermaPure, model FC125-240$5 \mathrm{mp}$ ) followed by dilution with 1.0 LPM clean, dry air from the purge-gas generator. Particle size distributions of the dry particles were measured by scanning mobility particle sizer (SMPS), made up of a classifier (TSI; Model 3080), differential mobility analyzer (TSI; Model 3081) and condensation particle counter (TSI; Model 3776). The atomized particles had a broad size distribution from 15 to $300 \mathrm{~nm}$, which includes typical sizes of ambient particles. The known density of $\left(\mathrm{NH}_{4}\right)_{2} \mathrm{SO}_{4}$ was then used to calculate the number of molecules of $\mathrm{NH}_{4}^{+}$in the particle phase per cubic centimeter of air. Samples from this flow were taken using highconcentration cartridges at 1.0 LPM for $20 \mathrm{~min}$ and analyzed as described in Sect. 2.3. A comparison of the measured $\mathrm{NH}_{4}^{+}$ to that calculated from the average particle size distribution results in a collection efficiency for particle-phase $\mathrm{NH}_{4}^{+}$ of $0.91 \pm 0.34(1 \mathrm{~s})$. (The major portion of the uncertainty 


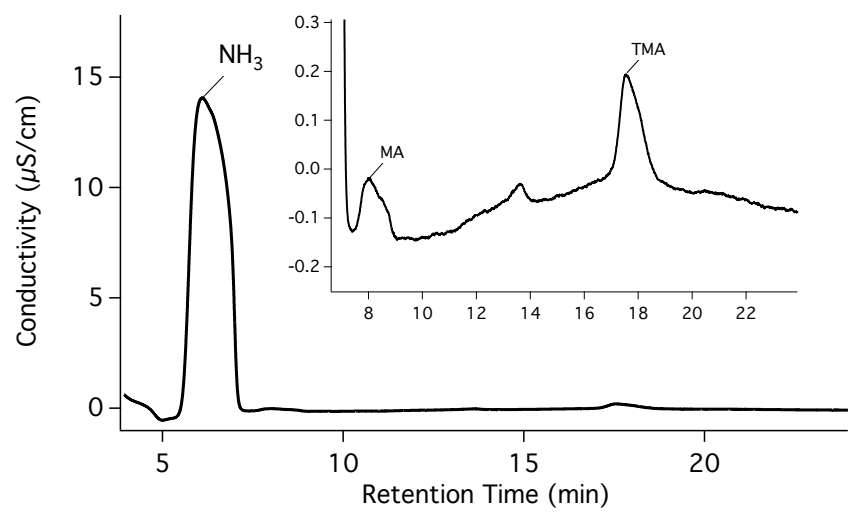

Figure 7. The background-subtracted chromatogram from the first extract of the cartridge for the sample taken 28 August 2013 at 4:22 a.m. in Chino, CA. Inset: same chromatogram magnified to show peaks for MA and TMA.

comes from the variability in the measured size distributions over the course of the experiment.)

In experiments at $\sim 30 \% \mathrm{RH}$, the diluent air was flowed through a bubbler filled with nanopure water. Highconcentration cartridge samples were taken as described above. The average size distribution for dry particles along with the associated uncertainty was used to calculate efficiency, as the presence of water would affect such a calculation under wet conditions. The same sampling efficiency of $0.91 \pm 0.34(1 \mathrm{~s})$ for $\mathrm{NH}_{4}^{+}$under $30 \% \mathrm{RH}$ was found by this method.

\subsection{Results for field measurements using low-concentration cartridges}

A typical chromatogram from an air sample taken in Chino, CA, on 28 August 2013 is shown in Fig. 7. On each of the three days of sampling (28 August, 4 and 12 September 2013), two 45-50 min samples were taken. The results from all field measurements which includes a combination of gases and particles are presented in Table 2. Also included in Table 2 are the temperature, relative humidity and weather conditions for each sample as reported by NOAA for the Chino Airport, which is $<1$ mile away from the sampling site (NOAA, 2014).

In all samples, peaks corresponding to $\mathrm{NH}_{3}$ and TMA were observed, with ammonia in the range of $0.19-1.5 \mathrm{ppm}$ and TMA in the range from 1.3 to $6.8 \mathrm{ppb}$. In several samples a peak for MA and/or a peak at $\sim 14$ min were present. In addition to the standards described in Sect. 2.1, those for isopropylamine, ethylamine, diethylamine, butylamine and aniline were obtained and analyzed by IC. However, their retention times did not correspond to the peak at $\sim 14 \mathrm{~min}$, which remains unidentified. Also, diethylamine has been reported to coelute with TMA in some Dionex IC columns (Murphy et al., 2007; VandenBoer et al., 2011, 2012). However, using the

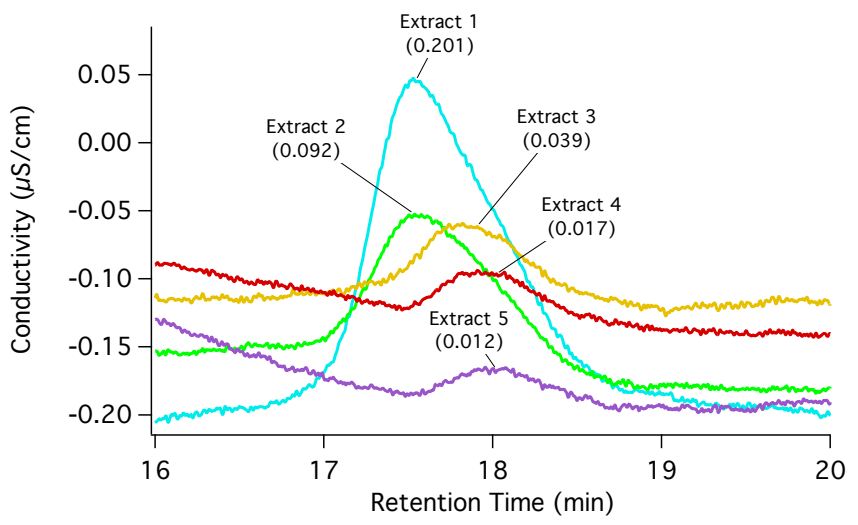

Figure 8. The background-subtracted chromatograms from all five extracts of the cartridge for the sample taken 28 August 2013 at 5:08 a.m. in Chino, CA. Image is magnified to show TMA peak. Integrated peak areas in $(\mu \mathrm{S} \mathrm{min}) \mathrm{cm}^{-1}$ are shown in parentheses. The slight shift in retention time at lower peak size was typical for TMA in both standards and samples.

Metrohm column and IC conditions described in Sect. 2.3, these two species were sufficiently well resolved to identify.

Each sample cartridge was extracted in-line and analyzed by IC five times. The TMA peaks for the five extracts from a sample taken on 28 August 2013 are shown in Fig. 8. The trend in integrated peak areas with extraction for TMA (shown in parentheses in Fig. 8) indicates that five extractions are necessary to measure $>97 \%$ of the collected species. Results for ammonia show the same trend. While ammonia and TMA peaks were usually still present in the fifth extract, they represented $3 \pm 2 \%(2 \mathrm{~s})$ for $\mathrm{NH}_{3}$ and $1 \pm 3 \%(2 \mathrm{~s})$ for TMA of the total over five extractions. However, the need for five extractions $(\sim 2.5 \mathrm{~h}$ IC run time) is a limitation of this method over existing on-line techniques. Optimization of this method (e.g., modifying cartridge dimensions, extraction solvent, IC parameters) may be able to reduce the number of required extractions, thereby reducing the time required for analysis.

The laboratory characterization of this technique was performed under dry conditions and showed near $100 \%$ collection efficiency as indicated by the small amount of analyte collected on the backup cartridges (Fig. 6). It is possible that ambient sampling at higher RH would reduce this efficiency, although this seems unlikely as WCE resin is designed and primarily used for extracting ions from liquid samples. Also, though the cartridges are flushed with clean, dry air prior to use, some residual water remains, which would exceed any water vapor in the gas-phase samples. For these reasons, the $\mathrm{RH}$ of the ambient samples is expected to have little effect on the measurement efficiency.

The first measurement on 12 September 2013 showed noticeably lower ammonia and TMA concentrations compared to the previous sampling periods. Several factors may contribute to this difference. The temperature was lower and 
Table 2. Results of field measurements taken in Chino, CA, along with weather data from NOAA ${ }^{\mathrm{a}}$ for the Chino Airport

\begin{tabular}{llrrrrr}
\hline $\begin{array}{l}\text { Date } \\
(2013)\end{array}$ & $\begin{array}{l}\text { Start } \\
\text { time }\end{array}$ & $\begin{array}{r}\text { Duration } \\
(\mathrm{min})\end{array}$ & $\begin{array}{r}{\left[\mathrm{NH}_{3}\right]} \\
(\mathrm{ppm})\end{array}$ & $\begin{array}{r}{[\mathrm{TMA}]} \\
(\mathrm{ppb})\end{array}$ & $\begin{array}{r}\text { Temperature } \\
\left({ }^{\circ} \mathrm{C}\right)\end{array}$ & $\begin{array}{r}\text { Relative humidity } \\
(\%)\end{array}$ \\
\hline 28 Aug & $4: 22$ a.m. & 45 & 0.90 & 6.8 & 21.1 & 57 \\
28 Aug & $5: 08$ a.m. & 45 & 1.5 & 6.7 & 20.6 & $57^{\mathrm{b}}$ \\
4 Sep & $3: 55$ a.m. & 50 & 0.75 & 4.0 & 21.1 & 71 \\
4 Sep & $4: 47$ a.m. & 50 & 0.75 & 3.3 & 20.6 & 79 \\
12 Sep & 3:53 a.m. & 50 & 0.19 & 1.3 & 15.0 & $93^{\mathrm{c}}$ \\
12 Sep & $4: 45$ a.m. & 50 & 0.49 & 4.5 & 14.4 & $90^{\mathrm{c}}$ \\
\hline
\end{tabular}

a Available at http://cdo.ncdc.noaa.gov/qclcd/QCLCD; ${ }^{\mathrm{b}}$ haze; ${ }^{\mathrm{c}}$ mist.

the relative humidity higher on 12 September compared to the two previous sampling days. Also, mist was reported by the Chino Airport weather station on 12 September that had completely cleared up sometime between 5:38 and 5:53 a.m. Wet deposition of mist droplets could account for the lower atmospheric $\mathrm{NH}_{3}$ and TMA concentrations on this day, and also explain the increase in concentration between the first and second sample as evaporation of deposited mist droplets occurred.

The results of these field measurements are consistent with the range of published data on ammonia and amine concentrations in agricultural areas. Concentrations of ammonia and TMA near cattle feedlots and enclosures in the range of 0.7-34 ppm $\mathrm{NH}_{3}$ (Hiranuma et al., 2010; Huang et al., 2009; Trabue et al., 2011) and 0-400 ppt TMA (Fujii and Kitai, 1987; Kuwata et al., 1983; Trabue et al., 2011) have been reported. Inside cattle enclosures, TMA concentrations up to 0.6-7.6 ppb have been measured (Fujii and Kitai, 1987; Kallinger and Niessner, 1999; Kuhn et al., 2011). The ratio of TMA to $\mathrm{NH}_{3}$ in this study, (4-9) $\times 10^{-3}$, is similar to that reported for indoor cattle enclosures as well as emissions from hay and silage (Kuhn et al., 2011).

\section{Conclusions}

This technique involving weak cation exchange resin as a substrate for collection of gas-phase ammonia and amines offers an accurate, reproducible, and inexpensive means of measurement at atmospherically relevant concentrations that is useful for both laboratory and field studies. It minimizes losses on inlets and sampling lines, and avoids uptake of aqueous amines onto glass surfaces. In addition, it is simple and relatively easy to implement, and uses commonly available instrumentation. The custom-designed high-pressure cartridge used as a carrier for the resin combined with a technique for in-line extraction of the compounds and analysis by ion chromatography gives detection limits in the tens of parts per trillion range.
Acknowledgements. The authors are grateful to Greg DeMattia and Metrohm USA for helpful discussions and access to the ion chromatography equipment and Lee Moritz and the UCI machine shop for fabricating the cartridge inserts. M. Dawson thanks Metrohm USA and the ARCS Foundation for scholarships. A. Gomez was supported by the NIH MARC program at Cal State LA (grant \#GM08228). This work was performed under a grant from the Department of Energy (grant \#ER65208).

Edited by: G. Phillips

\section{References}

Akyüz, M.: Simultaneous determination of aliphatic and aromatic amines in ambient air and airborne particulate matters by gas chromatography-mass spectrometry, Atmos. Environ., 42, 38093819, 2008.

Almeida, J., Schobesberger, S., Kürten, A., Ortega, I. K., Kupiainen-Määttä, O., Praplan, A. P., Adamov, A., Amorim, A., Bianchi, F., Breitenlechner, M., David, A., Dommen, J., Donahue, N. M., Downard, A., Dunne, E., Duplissy, J., Ehrhart, S., Flagan, R. C., Franchin, A., Guida, R., Hakala, J., Hansel, A., Heinritzi, M., Henschel, H., Jokinen, T., Junninen, H., Kajos, M., Kangasluoma, J., Keskinen, H., Kupc, A., Kurtén, T., Kvashin, A. N., Laaksonen, A., Lehtipalo, K., Leiminger, M., Leppä, J., Loukonen, V., Makhmutov, V., Mathot, S., McGrath, M. J., Nieminen, T., Olenius, T., Onnela, A., Petäjä, T., Riccobono, F., Riipinen, I., Rissanen, M., Rondo, L., Ruuskanen, T., Santos, F. D., Sarnela, N., Schallhart, S., Schnitzhofer, R., Seinfeld, J. H., Simon, M., Sipilä, M., Stozhkov, Y., Stratmann, F., Tomé, A., Tröstl, J., Tsagkogeorgas, G., Vaattovaara, P., Viisanen, Y., Virtanen, A., Vrtala, A., Wagner, P. E., Weingartner, E., Wex, H., Williamson, C., Wimmer, D., Ye, P., Yli-Juuti, T., Carslaw, K. S., Kulmala, M., Curtius, J., Baltensperger, U., Worsnop, D. R., Vehkamäki, H., and Kirkby, J.: Molecular understanding of sulphuric acid-amine particle nucleation in the atmosphere, Nature, 502, 359-363, 2013.

Anderson, N., Strader, R., and Davidson, C.: Airborne reduced nitrogen: ammonia emissions from agriculture and other sources, Environ. Int., 29, 277-286, 2003.

Angelino, S., Suess, D., and Prather, K.: Formation of aerosol particles from reactions of secondary and tertiary alkylamines: Characterization by aerosol time-of-flight mass spectrometry, Environ. Sci. Technol., 35, 3130-3138, 2001. 
Barsanti, K. C., McMurry, P. H., and Smith, J. N.: The potential contribution of organic salts to new particle growth, Atmos. Chem. Phys., 9, 2949-2957, doi:10.5194/acp-9-2949-2009, 2009.

Bates, T., Lamb, B., Guenther, A., Dignon, J., and Stoiber, R.: Sulfur emissions to the atmosphere from natural sources, J. Atmos. Chem., 14, 315-337, 1992.

Berndt, T., Stratmann, F., Sipilä, M., Vanhanen, J., Petäjä, T., Mikkilä, J., Grüner, A., Spindler, G., Lee Mauldin III, R., Curtius, J., Kulmala, M., and Heintzenberg, J.: Laboratory study on new particle formation from the reaction $\mathrm{OH}+\mathrm{SO}_{2}$ : influence of experimental conditions, $\mathrm{H}_{2} \mathrm{O}$ vapour, $\mathrm{NH}_{3}$ and the amine tert-butylamine on the overall process, Atmos. Chem. Phys., 10, 7101-7116, doi:10.5194/acp-10-7101-2010, 2010.

Borduas, N., Abbatt, J. P. D., and Murphy, J. G.: Gas phase oxidation of monoethanolamine (MEA) with $\mathrm{OH}$ radical and ozone: kinetics, products, and particles, Environ. Sci. Technol., 47, 6377-6383, 2013.

Bzdek, B. R. and Johnston, M. V.: New particle formation and growth in the troposphere, Anal. Chem., 82, 7871-7878, 2010.

Bzdek, B. R., Ridge, D. P., and Johnston, M. V.: Amine exchange into ammonium bisulfate and ammonium nitrate nuclei, Atmos. Chem. Phys., 10, 3495-3503, doi:10.5194/acp-10-3495-2010, 2010.

Bzdek, B. R., Ridge, D. P., and Johnston, M. V.: Reactivity of methanesulfonic acid salt clusters relevant to marine air, J. Geophys. Res.-Atmos., 116, D03301, doi:10.1029/2010JD015217, 2011.

Chan, L. P. and Chan, C. K.: Displacement of ammonium from aerosol particles by uptake of triethylamine, Aerosol Sci. Technol., 46, 236-247, 2012.

Chen, M., Titcombe, M., Jiang, J., Jen, C., Kuang, C., Fischer, M. L., Eisele, F. L., Siepmann, J. I., Hanson, D. R., Zhao, J., and McMurry, P. H.: Acid-base chemical reaction model for nucleation rates in the polluted atmospheric boundary layer, Proc. Natl. Aca. Sci., 109, 18713-18718, 2012.

Creamean, J. M., Ault, A. P., Ten Hoeve, J. E., Jacobson, M. Z., Roberts, G. C., and Prather, K. A.: Measurements of aerosol chemistry during new particle formation events at a remote rural mountain site, Environ. Sci. Technol., 45, 8208-8216, 2011.

Dawson, M. L., Varner, M. E., Perraud, V., Ezell, M. J., Gerber, R. B., and Finlayson-Pitts, B. J.: Simplified mechanism for new particle formation from methanesulfonic acid, amines, and water via experiments and $a b$ initio calculations, Proc. Natl. Aca. Sci., 109, 18719-18724, 2012.

Fehsenfeld, F. C., Huey, L. G., Leibrock, E., Dissly, R., Williams, E., Ryerson, T. B., Norton, R., Sueper, D. T., and Hartsell, B.: Results from an informal intercomparison of ammonia measurement techniques, J.-Geophys.-Res., 107, 4812, 2002.

Feilberg, A., Liu, D., Adamsen, A. P. S., Hansen, M. J., and Jonassen, K. E. N.: Odorant emissions from intensive pig production measured by online proton-transfer-reaction mass spectrometry, Environ. Sci. Technol., 44, 5894-5900, 2010.

Fenn, M. E., Poth, M. A., and Arbaugh, M. J.: A throughfall collection method using mixed bed ion exchange resin columns, The Scientific World Journal, 2, 122-130, 2002.

Finlayson-Pitts, B. J. and Pitts, J. N.: Chemistry of the upper and lower atmosphere - theory, experiments and applications, Academic Press, San Diego, 2000.
Fournier, M., Lesage, J., Ostiguy, C., and Van Tra, H.: Sampling and analytical methodology development for the determination of primary and secondary low molecular weight amines in ambient air, J. Environ. Monit., 10, 379-386, 2008.

Fujii, T. and Kitai, T.: Determination of trace levels of trimethylamine in air by gas chromatography/surface ionization organic mass spectrometry, Anal. Chem., 59, 379-382, 1987.

Fuselli, S., Benedetti, G., and Mastrangeli, R.: Determination of methylamines in air using activated-charcoal traps and gaschromatographic analysis with an alkali flame detector (AFD), Atmos. Environ., 16, 2943-2946, 1982.

Ge, X., Wexler, A., and Clegg, S.: Atmospheric amines - Part I, A review, Atmos. Environ., 45, 524-546, $2011 \mathrm{a}$.

Ge, X., Wexler, A., and Clegg, S.: Atmospheric amines - Part II, Thermodynamic properties and gas/particle partitioning, Atmos. Environ., 45, 561-577, 2011b.

Gibb, S. W., Mantoura, R. F. C., and Liss, P. S.: Ocean-atmosphere exchange and atmospheric speciation of ammonia and methylamines in the region of the NW Arabian Sea, Global Biogeochem. Cy., 13, 161-177, 1999.

Gronberg, L., Lovkvist, P., and Jonsson, J.: Determination of aliphatic-amines in air by membrane enrichment directly coupled to a gas-chromatograph, Chromatographia, 33, 77-82, 1992.

Hansen, M. J., Adamsen, A. P. S., and Feilberg, A.: Recovery of odorants from an olfactometer measured by proton-transferreaction mass spectrometry, Sensors, 13, 7860-7871, 2013.

Hanson, D. R., McMurry, P. H., Jiang, J., Tanner, D., and Huey, L. G.: Ambient pressure proton transfer mass spectrometry: detection of amines and ammonia, Environ. Sci. Technol., 45, 88818888, 2011.

Haynes, W. M. (Ed.): Dissociation constants of organic acids and bases, CRC Handbook of Chemistry and Physics, available at: http://www.hbcpnetbase.com/ (last access: 29 April 2013), 2013.

Hiranuma, N., Brooks, S. D., Thornton, D. C. O., and Auvermann, B. W.: Atmospheric ammonia mixing ratios at an open-air cattle feeding facility, J. Air Waste Manage. Assoc., 60, 210-218, 2010.

Huang, G., Hou, J., and Zhou, X.: A measurement method for atmospheric ammonia and primary amines based on aqueous sampling, OPA derivatization and HPLC analysis, Environ. Sci. Technol., 43, 5851-5856, 2009.

Kallinger, G. and Niessner, R.: Laboratory investigation of annular denuders as sampling system for the determination of aliphatic primary and secondary amines in stack gas, Mikrochim Acta, 130, 309-316, 1999.

Kirchner, M., Braeutigam, S., Ferm, M., Haas, M., Hangartner, M., Hofschreuder, P., Kasper-Giebl, A., Römmelt, H., Striedner, J., Terzer, W., Thöni, L., Werner, H., and Zimmerling, R.: Field intercomparison of diffusive samplers for measuring ammonia, J. Environ. Monit., 1, 259-265, 1999.

Kuhn, U., Sintermann, J., Spirig, C., Jocher, M., Ammann, C., and Neftel, A.: Basic biogenic aerosol precursors: Agricultural source attribution of volatile amines revised, Geophys. Res. Lett., 38, L16811, doi:10.1029/2011GL047958, 2011.

Kunin, R. and Barry, R. E.: Carboxylic, Weak Acid Type, Cation Exchange Resin, Ind. Eng. Chem., 41, 1269-1272, 1949.

Kuwata, K., Akiyama, E., Yamazaki, Y., Yamasaki, H., and Kuge, Y.: Trace determination of low molecular weight aliphatic amines in air by gas chromatograph, Anal. Chem., 55, 2199-2201, 1983. 
Li, Y., Schwab, J. J., and Demerjian, K. L.: Measurements of ambient ammonia using a tunable diode laser absorption spectrometer: Characteristics of ambient ammonia emissions in an urban area of New York City, J. Geophys. Res., 111, D10S02, doi:10.1029/2005JD006275, 2006.

Liu, D., Feilberg, A., Adamsen, A. P. S., and Jonassen, K. E. N.: The effect of slurry treatment including ozonation on odorant reduction measured by in-situ PTR-MS, Atmos. Environ., 45, 37863793, 2011.

Liu, Y., Han, C., Liu, C., Ma, J., Ma, Q., and He, H.: Differences in the reactivity of ammonium salts with methylamine, Atmos. Chem. Phys., 12, 4855-4865, doi:10.5194/acp-12-48552012, 2012.

Lloyd, J., Heaton, K., and Johnston, M.: Reactive uptake of trimethylamine into ammonium nitrate particles, J. Phys. Chem. A, 113, 4840-4843, 2009.

Lobert, J. M., Scharffe, D. H., Hao, W. M., and Crutzen, P. J.: Importance of biomass burning in the atmospheric budgets of nitrogencontaining gases, Nature, 346, 552-554, 1990.

Loukonen, V., Kurtén, T., Ortega, I. K., Vehkamäki, H., Pádua, A. A. H., Sellegri, K., and Kulmala, M.: Enhancing effect of dimethylamine in sulfuric acid nucleation in the presence of water - a computational study, Atmos. Chem. Phys., 10, 49614974, doi:10.5194/acp-10-4961-2010, 2010.

Markovic, M. Z., VandenBoer, T. C., and Murphy, J. G.: Characterization and optimization of an online system for the simultaneous measurement of atmospheric water-soluble constituents in the gas and particle phases, J. Environ. Monit., 14, 1872-1884, 2012.

Mosier, A., Andre, C., and Viets, F.: Identification of aliphatic amines volatilized from cattle feedyard, Environ. Sci. Technol., 7, 642-644, 1973.

Müller, C., Iinuma, Y., Karstensen, J., van Pinxteren, D., Lehmann, S., Gnauk, T., and Herrmann, H.: Seasonal variation of aliphatic amines in marine sub-micrometer particles at the Cape Verde islands, Atmos. Chem. Phys., 9, 9587-9597, doi:10.5194/acp-99587-2009, 2009.

Murphy, S. M., Sorooshian, A., Kroll, J. H., Ng, N. L., Chhabra, P., Tong, C., Surratt, J. D., Knipping, E., Flagan, R. C., and Seinfeld, J. H.: Secondary aerosol formation from atmospheric reactions of aliphatic amines, Atmos. Chem. Phys., 7, 2313-2337, doi:10.5194/acp-7-2313-2007, 2007.

Ni, J.-Q., Robarge, W. P., Xiao, C., and Heber, A. J.: Volatile organic compounds at swine facilities: A critical review, Chemosphere, 89, 769-788, 2012.

Nielsen, C. J., Herrmann, H., and Weller, C.: Atmospheric chemistry and environmental impact of the use of amines in carbon capture and storage (CCS), Chem. Soc. Rev., 41, 6684-6704, 2012.

Nishikawa, T. and Kuwata, K.: Liquid chromatographic determination of low molecular weight aliphatic amines in air via derivatization with 7-chloro-4-nitro-2,1,3-benzoxadiazole, Anal. Chem., 56, 1790-1793, 1984.

Nishino, N., Arquero, K. D., Dawson, M. L., and Finlayson-Pitts, B. J.: Infrared studies of the reaction of methanesulfonic acid with trimethylamine on surfaces, Environ. Sci. Technol., 48, 323-330, 2013.
NOAA: Quality Controlled Local Climatological Data, NOAA, available at: http://cdo.ncdc.noaa.gov/qclcd/QCLCD (last access: 6 January 2014), 2014.

Norman, M., Spirig, C., Wolff, V., Trebs, I., Flechard, C., Wisthaler, A., Schnitzhofer, R., Hansel, A., and Neftel, A.: Intercomparison of ammonia measurement techniques at an intensively managed grassland site (Oensingen, Switzerland), Atmos. Chem. Phys., 9, 2635-2645, doi:10.5194/acp-9-2635-2009, 2009.

Orsini, D. A., Ma, Y., Sullivan, A., Sierau, B., Baumann, K., and Weber, R. J.: Refinements to the particle-into-liquid sampler (PILS) for ground and airborne measurements of water soluble aerosol composition, Atmos. Environ., 37, 1243-1259, 2003.

Perrino, C., Catrambone, M., Di Menno Di Bucchianico, A., and Allegrini, I.: Gaseous ammonia in the urban area of Rome, Italy and its relationship with traffic emissions, Atmos. Environ., 36, 5385-5394, 2002.

Praplan, A. P., Bianchi, F., Dommen, J., and Baltensperger, U.: Dimethylamine and ammonia measurements with ion chromatography during the CLOUD4 campaign, Atmos. Meas. Tech., 5, 2161-2167, doi:10.5194/amt-5-2161-2012, 2012.

Rochelle, G. T.: Amine Scrubbing for $\mathrm{CO}_{2}$ Capture, Science, 325 , 1652-1654, 2009.

Ruiz-Jiménez, J., Hautala, S., Parshintsev, J., Laitinen, T., Hartonen, K., Petäjä, T., Kulmala, M., and Riekkola, M.-L.: Aliphatic and aromatic amines in atmospheric aerosol particles: Comparison of three ionization techniques in liquid chromatography-mass spectrometry and method development, Talanta, 97, 55-62, 2012.

Santagati, N. A., Bousquet, E., Spadaro, A., and Ronsisvalle, G.: Analysis of aliphatic amines in air samples by HPLC with electrochemical detection, J. Pharm. Biomed. Anal., 29, 1105-1111, 2002.

Schade, G. and Crutzen, P.: Emission of aliphatic amines from animal husbandry and their reactions: Potential source of $\mathrm{N}_{2} \mathrm{O}$ and HCN, J. Atmos. Chem., 22, 319-346, 1995.

Scheiner, D.: Determination of ammonia and Kjeldahl nitrogen by indophenol method, Water Res., 10, 31-36, 1976.

Schreiber, A., Zapp, P., and Kuckshinrichs, W.: Environmental assessment of German electricity generation from coal-fired power plants with amine-based carbon capture, Int. J. Life Cycle Assess., 14, 547-559, 2009.

Schwab, J. J., Li, Y., Bae, M.-S., Demerjian, K. L., Hou, J., Zhou, X., Jensen, B., and Pryor, S. C.: A Laboratory Intercomparison of Real-Time Gaseous Ammonia Measurement Methods, Environ. Sci. Technol., 41, 8412-8419, 2007.

Seinfeld, J. H. and Pandis, S. N.: Atmospheric chemistry and physics: from air pollution to climate change, WileyInterscience, 2006.

Simkin, S. M., Lewis, D. N., Weathers, K. C., Lovett, G. M., and Schwarz, K.: Determination of Sulfate, Nitrate, and Chloride in Throughfall using Ion-Exchange Resins, Water Air Soil Pollut., 153, 343-354, 2004.

Skogley, E. O. and Dobermann, A.: Synthetic ion-exchange resins: Soil and environmental studies, J. Environ. Qual., 25, 13-24, 1996.

Skoog, D. A., Holler, F. J., and Nieman, T. A.: Principles of Instrumental Analysis, 5th Edn., Harcourt Brace \& Company, Orlando, FL., 1998.

Smith, J., Barsanti, K., Friedli, H., Ehn, M., Kulmala, M., Collins, D., Scheckman, J., Williams, B., and McMurry, P.: Observations 
of aminium salts in atmospheric nanoparticles and possible climatic implications, Proc. Natl. Aca. Sci., 107, 6634-6639, 2010.

Solórzano, L.: Determination of ammonia in natural waters by the phenol hypochlorite method, Limnol. Oceanogr., 14, 799-801, 1969.

Sutton, M. A., Dragosits, U., Tang, Y. S., and Fowler, D.: Ammonia emissions from non-agricultural sources in the UK, Atmos. Environ., 34, 855-869, 2000.

Tang, X., Price, D., Praske, E., Lee, S. A., Shattuck, M. A., PurvisRoberts, K., Silva, P. J., Asa-Awuku, A., and Cocker, D. R.: $\mathrm{NO}_{3}$ radical, $\mathrm{OH}$ radical and $\mathrm{O}_{3}$-initiated secondary aerosol formation from aliphatic amines, Atmos. Environ., 72, 105-112, 2013.

Tanimoto, H., Aoki, N., Inomata, S., Hirokawa, J., and Sadanaga, Y.: Development of a PTR-TOFMS instrument for real-time measurements of volatile organic compounds in air, Int. J. Mass Spectrom., 263, 1-11, 2007.

Templer, P. H. and Weathers, K. C.: Use of mixed ion exchange resin and the denitrifier method to determine isotopic values of nitrate in atmospheric deposition and canopy throughfall, Atmos. Environ., 45, 2017-2020, 2011.

Ten Brink, H., Otjes, R., Jongejan, P., and Slanina, S.: An instrument for semi-continuous monitoring of the size-distribution of nitrate, ammonium, sulphate and chloride in aerosol, Atmos. Environ., 41, 2768-2779, 2007.

Toda, K., Koga, T., Tanaka, T., Ohira, S.-I., Berg, J. M., and Dasgupta, P. K.: Miniature open channel scrubbers for gas collection, Talanta, 82, 1870-1875, 2010.

Trabue, S., Scoggin, K., McConnell, L., Maghirang, R., Razote, E. and Hatfield, J.: Identifying and tracking key odorants from cattle feedlots, Atmos. Environ., 45, 4243-4251, 2011.

Trebs, I., Meixner, F. X., Slanina, J., Otjes, R., Jongejan, P., and Andreae, M. O.: Real-time measurements of ammonia, acidic trace gases and water-soluble inorganic aerosol species at a rural site in the Amazon Basin, Atmos. Chem. Phys., 4, 967-987, doi:10.5194/acp-4-967-2004, 2004.

VandenBoer, T. C., Markovic, M. Z., Petroff, A., Czar, M. F., Borduas, N., and Murphy, J. G.: Ion chromatographic separation and quantitation of alkyl methylamines and ethylamines in atmospheric gas and particulate matter using preconcentration and suppressed conductivity detection, J. Chromatogr. A, 1252, 7483, 2012.
VandenBoer, T. C., Petroff, A., Markovic, M. Z., and Murphy, J. G.: Size distribution of alkyl amines in continental particulate matter and their online detection in the gas and particle phase, Atmos. Chem. Phys., 11, 4319-4332, doi:10.5194/acp-11-43192011, 2011.

von Bobrutzki, K., Braban, C. F., Famulari, D., Jones, S. K., Blackall, T., Smith, T. E. L., Blom, M., Coe, H., Gallagher, M., Ghalaieny, M., McGillen, M. R., Percival, C. J., Whitehead, J. D., Ellis, R., Murphy, J., Mohacsi, A., Pogany, A., Junninen, H., Rantanen, S., Sutton, M. A., and Nemitz, E.: Field inter-comparison of eleven atmospheric ammonia measurement techniques, Atmos. Meas. Tech., 3, 91-112, doi:10.5194/amt-3-91-2010, 2010.

Wang, L., Lal, V., Khalizov, A. F., and Zhang, R.: Heterogeneous chemistry of alkylamines with sulfuric acid: implications for atmospheric formation of alkylaminium sulfates, Environ. Sci. Technol., 44, 2461-2465, 2010.

Whitehead, J. D., Longley, I. D., and Gallagher, M. W.: Seasonal and Diurnal Variation in Atmospheric Ammonia in an Urban Environment Measured Using a Quantum Cascade Laser Absorption Spectrometer, Water Air Soil Pollut., 183, 317-329, 2007.

Wiebe, H. A., Anlauf, K. G., Tuazon, E. C., Winer, A. M., Biermann, H. W., Appel, B. R., Solomon, P. A., Cass, G. R., Ellestad, T. G., Knapp, K. T., Peake, E., Spicer, C. W., and Lawson, D. R.: A comparison of measurements of atmospheric ammonia by filter packs, transition-flow reactors, simple and annular denuders and fourier transform infrared spectroscopy, Atmos. Environ., 24, 1019-1028, 1990.

Williams, E., Sandholm, S., Bradshaw, J., Schendel, J., Langford, A., Quinn, P., Lebel, P., Vay, S., Roberts, P., Norton, R., Watkins, B., Buhr, M., Parrish, D., Calvert, J., and Fehsenfeld, F.: An Intercomparison of 5 Ammonia Measurement Techniques, J. Geophys. Res.-Atmos., 97, 11591-11611, 1992.

Yu, H. and Lee, S.-H.: Chemical ionisation mass spectrometry for the measurement of atmospheric amines, Environ. Chem., 9, 190-201, 2012.

Yu, H., McGraw, R., and Lee, S.-H.: Effects of amines on formation of sub-3 nm particles and their subsequent growth, Geophys. Res. Lett., 39, doi:10.1029/2011GL050099, 2012.

Zhang, G., Dasgupta, P. K., and Shen, D.: Measurement of atmospheric ammonia, Environ. Sci. Technol., 23, 1467-1474, 1989. 